\title{
IMPLEMENTASI E-COMMERCE DENGAN METODE BUSINESS MODEL CANVAS (BMC) MENGGUNAKAN CONTENT MANAGEMENT SYSTEM (CMS) UNTUK MENINGKATKAN PENJUALAN PADA DISTRO BETAWI BOYS
}

\author{
Fatur Ristia Padillah ${ }^{1}$, Anita Diana $^{2 *}$, Atik Ariesta ${ }^{3}$ \\ ${ }^{1,2}$ Fakultas Teknologi Informasi, Sistem Informasi, Universitas Budi Luhur, Jakarta, Indonesia \\ ${ }^{3}$ Fakultas Teknologi Informasi, Manajemen Informatika, Universitas Budi Luhur, Jakarta, Indonesia \\ Email: ${ }^{1}$ faturistia@gmail.com, ${ }^{2 *}$ anita.diana@budiluhur.ac.id, ${ }^{3}$ atik.ariesta@budiluhur.ac.id
}

\begin{abstract}
Abstrak-Distro Betawi Boys bergerak dibidang fashion dengan desain Betawi modern. Penjualannya dilakukan melalui offline dan media sosial. Beberapa kendala yang dihadapi, penurunan penjualan, karena pelanggan tidak dapat datang langsung dimasa pandemi COVID-19. Kemudian, media promosi penjualan dan pemasaran kurang maksimal, melalui media sosial, melalui orang ke orang dan dari brosur atau spanduk. Lalu proses transaksi belum menyediakan kwitansi pembayaran sehingga belum ada bukti penjualan dan pembayaran. Kendala lainnya, pencatatan penjualan belum tersimpan dengan baik, sehingga memakan waktu lebih lama untuk update stok produk. Untuk mengatasi kendala-kendala tersebut, dibutuhkan media tambahan sebuah website ecommerce. Dalam pengembangannya menggunakan metode Business Model Canvas (BMC) untuk menganalisa kekuatan dan kekurangan bisnisnya. Perancangan sistem menggunakan metode Unified Modelling Language (UML), dan websitenya menggunakan Content Management System (CMS) Wordpress. Kemudian dioptimalisasi dengan penerapan Search Engine Optimization (SEO) agar website berada dihalaman awal mesin pencari, sehingga memudahkan pelanggan untuk menemukan situs tersebut. Website e-commerce yang dihasilkan diharapkan dapat meningkatkan penjualan produk dan mempermudah pembelian secara online, menyajikan bukti penjualan dan pembayaran informasi untuk konsumen, melalui notifikasi email, serta menampilkan stok produk untuk mengetahui update produk baru kepada calon pelanggan. Penerapan SEO dan marketing pada website ecommerce, memudahkan pencarian pada mesin pencari, dan memperluas pemasaran.
\end{abstract}

Kata Kunci: Fashion, Business Model Canvas, e-commerce, Content Management System, SEO.

\begin{abstract}
Betawi Boys distribution is engaged in fashion with modern Betawi designs. Sales are made through offline and social media. Some of the obstacles faced, decreased sales, because customers could not come directly during the COVID-19 pandemic. Then, sales promotion and marketing media are less than optimal, through social media, through person to person and from brochures or banners. Then the transaction process has not provided a payment receipt so there is no proof of sale and payment. Another obstacle is that sales records have not been stored properly, so it takes longer to update product stock. To overcome these obstacles, an additional media is needed for an e-commerce website. In its development, it uses the Business Model Canvas (BMC) method to analyze its business strengths and weaknesses. The system design uses the Unified Modelling Language (UML) method, and the website uses a WordPress Content Management System (CMS). Then it is optimized by implementing Search Engine Optimization (SEO) so that the website is on the first page of search engines, making it easier for customers to find the site. The resulting e-commerce website is expected to increase product sales and facilitate online purchases, provide proof of sales and payment information for consumers, via email notifications, and display product stock to find out new product updates to potential customers. Implementing SEO and marketing on e-commerce websites, making it easier to search on search engines, and expanding marketing.
\end{abstract}

Keywords: Fashion, Content Management System, Business Model Canvas, E-commerce, SEO.

\section{PENDAhUluAN}

Dalam dunia teknologi dan informasi, E-Commerce atau Electronic Commerce umumnya dapat diartikan sebagai proses transaksi jual beli yang dilakukan secara elektronik melalui aktifitas penyebaran, penjualan, pembelian, pemasaran dengan memanfaatkan jaringan telekomunikasi media internet. Dalam melakukan transaksi secara online penggunaan internet menjadi pilihan untuk kemudahan dalam berbisnis. E-Commerce menjadi pilihan dengan adanya informasi dalam bentuk yang lebih menarik, serta dapat diakses dimanapun dan kapanpun secara online. Konsep toko online yang menyediakan banyak kemudahan dan kelebihan dalam pembelian maupun penjualan jika dibandingkan dengan konsep belanja yang tradisional seperti saat ini. Terutama dimasa pandemic Covid-19 ini, masyarakat dibatasi aktifitas nya, sehingga sulit melakukan pembelian langsung ke toko. Oleh karena itu, dibutuhkan media tambahan $e$ commerce berbentuk website agar memudahkan pembelian online jarak jauh. Distro Betawi Boys adalah sebuah usaha bisnis fashion tradisional yang bergerak dalam bidang penjualan seperti baju, hoodie, dan celana, dengan desain Betawi modern`. Distro Betawi Boys memasarkan semua produk melalui media social jaringan seperti Instagram, Whatsapp dan Shoppe yang beralamat di username@distro.betawiboys, dimana pelanggan yang berminat untuk 
pembelian produk dapat mengunjungi toko dan melalui media social seperti Instagram, Whatsapp, dan Shopee dari toko Distro Betawi Boys.

Beberapa kendala yang dihadapi oleh Distro Betawi Boys, antara lain pelanggan yang tidak dapat datang langsung ke toko dimasa pandemic COVID-19, sehingga terjadi penurunan penjualan. Selain itu, media promosi penjualan dan pemasaran yang kurang maksimal melalui media sosial, masih melalui orang ke orang dan dari brosur atau spanduk. Proses transaksi yang dilakukan belum menyediakan kwitansi pembayaran sehingga belum adanya bukti penjualan dan pembayaran untuk pelanggan. Kendala lainnya, pencatatan penjualan yang belum tersimpan dengan baik, sehingga memakan waktu lebih lama untuk update stock produk. Untuk mengatasi kendala-kendala tersebut, dibutuhkan media tambahan sebuah e-commerce berbasis website. Pemilik toko ini mengharapkan dapat meningkatkan penjualan dan pemasaran dengan adanya website e-commerce. Dengan melalui e-commerce pelanggan bisa berinteraksi serta berperan dalam melakukan transaksi proses jual beli yang dilakukan tanpa dibatasi oleh tempat dan waktu. Selain itu, dengan adanya website e-commerce ini dapat memperluas pemasaran tanpa harus menghabiskan banyak waktu, biaya, dan tenaga. Sehingga hal tersebut juga dapat berdampak dalam meningkatkan proses penjualan yang terjadi pada Distro Betawi Boys.

Kosasi [1] menyatakan bahwa calon pelanggan mudah mengunjungi halaman situs website, karena ada fitur navigasi. Calon pelanggan dapat memesan barang dimanapun dan kapanpun secara online, dan cepat mendapatkan informasi yang dibutuhkan.

Metode yang dibangun untuk mengembangun website e-commerce menggunakan Business Model Canvas (BMC) untuk menganalisa kelemahan dan kekuatan bisnisnya. Perancangan sistem menggunakan metode Unifield Modeling Language (UML), dan websitenya menggunakan Content Management System (CMS) dengan Wordpress. Website e-commerce juga akan dioptimalisasi dengan menerapakan teknik Search Engine Optimization (SEO), untuk membantu dalam membuat website pada halaman awal mesin pencari, sehingga memudahkan pelanggan untuk menemukan situs tersebut.

Penelitian sebelumnya oleh [2] membahas implementasi $e$-commerce dibangun dengan menggunakan Content Management System untuk memasarakan produknya Lumi Distro. Penjualan pada Lumi Distro menjadi lebih maksimal dengan menampilkan fitur cart pada tampilan website e-commerce. Sehingga memudahkan pelanggan dalam memesan produk dimana saja dan kapan saja. Pemasaran menjadi lebih luas dengan penerapan Yoast SEO agar dapat terindex oleh google. Website Lumi Distro menjadi lebih unggul dengan pesaing distro lainnya.

Pada penelitian oleh [3] menyatakan bahwa sistem penjualan e-commerce pada Distro Dlapak Street Wear dengan berbasis website merupakan sebuah prototipe dimana aplikasi sistem yang digunakan sudah terkomputerisasi dibuat dengan berbasis website serta pengolahan database membuat data informasi dibuat secara terpusat, sehingga pengolahan database yang dilakukan tersebut agar menjadi sebuah informasi data yang akan dibutuhkan oleh para pengguna. Keuntungan ini dapat mengakses dari mana dan kapan saja melalui media jaringan internet, serta meningkatan efesiensi dan efektifitas untuk menyampaian informasi produk tanpa harus terhalang oleh waktu dan tempat.

Penelitian oleh [4] menyatakan bahwa dengan melalui website penjualan akan mempemudah Project Distro dalam memberikan informasi produk yang ada kepada calon pelanggan. Memudahkan pengguna untuk mendapatkan informasi yang update melalui media internet mengenai informasi produk fashion tanpa perlu datang ke toko. Dapat memudahkan user untuk melakukan pesanan maupun pembelian, sehingga user lebih mudah dan nyaman tanpa harus kehilangan biaya dan waktu untuk datang langsung ke toko dan juga meningkakan efektifitas dan efesiensi pengolahan proses data.

Dalam penelitian oleh [5] dinyatakan bahwa metode BMC digunakan agar dapat menyusun strategi toko supaya berbeda dari pesaingnya, serta dengan mudah dalam mengambil langkah untuk mencapai tujuan bisnisnya. Dengan adanya website e-commerce pada Distro Mr. Bro, dapat memperluas pemasaran dan memaksimalkan penjualan.

Dalam penelitian [6] mengemukakan bahwa dengan penjualan secara online dengan memanfaatkan internet, dapat menekan biaya yang dikeluarkan seperti biaya sewa tempat, penentuan titik strategi pemasaran, sampai dengan biaya listrik. Implementasi e-commerce berbasis website pada Distro Pak Eko, diharapkan agar proses transaksi jarak jauh memudahkan pelanggan yang tidak perlu datang ke toko distro langsung.

Pada penilitian oleh [7], implementasi sistem e-commerce berbasis website yang digunakan pada toko Asri Konvesi Collection, dibangun dengan menggunakan metode Business Model Canvas (BMC) dan Content Management System (CMS). Dalam tahap pengujian yang dilakukan mendapatkan hasil cukup baik serta dapat diterima pengguna. Sistem yang diterapkan dapat memudahkan pengguna untuk mendapatkan informasi data produk, serta dapat meningkatkan area pemasaran dan penjualan kepada pelanggan.

Kebutuhan dibangunnya website E-Commerce Distro Betawi Boys Tangerang adalah untuk mengatasi masalah yang terjadi didalam sebuah bisnis. Sistem website E-Commerce pada Distro Betawi Boys dengan menggunakan Content Management System (CMS) dan Wordpress. Penggunaannya yang dapat mempermudah dalam pembuatan dan pengaturan data maupun informasi tanpa harus mendalami HTML dalam membuat website tersebut. 
Dalam buku dituliskan oleh [8] E-Commerce dapat diartikan sebagai sarana dari proses transaksi yang dilakukan antara penjual dengan pembeli dimedia online. Dalam bukunya [9] menyatakan bahwa Content Management System $(C M S)$ berfungsi untuk menyimpan dokumen, gambar, video dan musik. Implementasi CMS dibuat untuk mengembangkan konten dari sebuah sistem agar dapat memenuhi kebutuhan dengan serangkain persyaratan khusus. Wordpress adalah sebuah aplikasi dari Content Management System (CMS) yang mudah digunakan oleh user. Dalam buku [10] menjelaskan Wordpress adalah aplikasi open source untuk CMS yang terkenal dan mudah digunakan oleh user dan Developer, Serta plugins yang terdapat pada Wordpress memudahkan dalam membuat tampilan menjadi lebih baik. Salah satunya menggunakan plugins pada Worpress yang sering digunakan adalah WooCommerce yang mempunyai berbagai macam fitur yang fleksibel sehingga memudahkan untuk penggunannya.

Website e-commerce yang dihasilkan diharapkan dapat meningkatkan hasil penjualan produk serta memudahkan pembelian secara online terutama dimasa pandemic COVID-19, tanpa harus datang langsung ke toko. Penerapan SEO dan marketing pada website e-commerce, memudahkan untuk ditemukan pada mesin pencari, dan memperluas pemasaran melalui internet. Website e-commerce yang dihasilkan, juga dapat menyajikan bukti penjualan dan pembayaran informasi untuk konsumen, melalui notifikasi email, serta fitur yang menampilkan tampilan stok produk yang update kepada pelanggan.

\section{METODE PENELITIAN}

\subsection{Metode Pengumpulan Data}

Pengumpulan data yang dilakukan adalah untuk memperoleh data sebagai informasi yang dibutuhkan untuk tercapainya suatu tujuan hasil dari penelitian. Berikut adalah metode-metode pengumpulan data yang telah dilakukan penulis yaitu:

a. Wawancara: kegiatan tanya jawab secara lisan secara langsung untuk memperoleh informasi antara dua pihak, pihak pertama sebagai pewawancara dan pihak kedua sebagai narasumber. Penulis mengajukan beberapa pertanyaan wawancara langsung dengan pemilik toko.

b. Observasi: pengamatan dilakukan terhadap objek sebuah penelitian secara langsung serta menarik kesimpulan dari seluruh kegiatan yang ada pada objek tersebut.

c. Analisa dokumen: merupakan kegiatan untuk menganalisa dokumen yang penulis lakukan untuk mendapatkan informasi data dari tempat riset. Dokumen yang didapatkan berkaitan dengan topik yang akan dibahas.

d. Studi literatur: merupakan kegiatan untuk menyelesaikan sumber-sumber yang dibuat penulis untuk mengetahui topik penelitian terdahulu yang sama dengan topik yang dibuat dengan cara membaca dan memahami isi daei refrensi yang diperoleh, maka penulis dapat mengetahui hasil penelitian yang pernah dibuat sebelumnya digunakan oleh penulis sebagai landasan perbandingan dengan sistem usulan yang akan dibuat.

\subsection{Tahapan Perancangan Bisnis}

Setelah melakukan pengumpulan data langkah berikutnya adalah dengan membuat rancangan bisnis yang dibuat dengan menggunakan metode Business Model Canvas terdapat 9 kolom pada gambar Business Model Canvas, tujuannya untuk mengetahui kelemahan dan kekuatan bisnis serta menganalisa kebutuhan data untuk mengetahui hasil kinerjak profit.

Business Model Canvas dikembangkan dan ditulis oleh Alexander Osterwalder, pada bukunya [11] menjelaskan $B M C$ dapat memudahkan organisasi pada bisnis yang akan dibuat oleh pengusaha untuk memulai bisnis. Penggunaan $B M C$ juga adalah sebagai media alat yang bertujuan untuk memahami sebuah proses bisnis secara lebih luas dan dapat menghasilkan kinerja yang baik, maka penggunaan Business Model Canvas juga menjadi gambaran sutau model proses bisnis. BMC memiliki 9 blok yang diterapkan, yaitu Key Activities, Key Resources, Key Partners, Value Proposition, Cost Struture, Channels, Revenue Streams Customer Segment, Customer Relationship. Kesembilan kolom tersebut terdapat dalam gambar $B M C$ yang dibuat dapat dilihat pada Gambar 1.

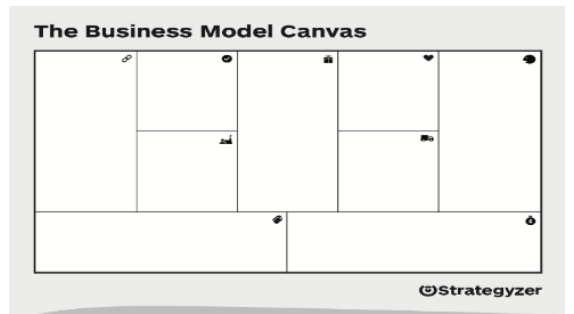

Gambar 1. 9 kolom Business Model Canvas (BMC) 
Pengaplikasian untuk menerapkan Search Engine Optimization dalam penelitian adalah sebagai mengoptimalkan ranking halaman awal website oleh mesin pencari. Untuk menerapkan Search Engine Optimiztaion dan marketing pada website e-commerce dapat memudahkan untuk ditemukan pada mesin pencari, dan memperluas pemasaran melalui internet.

\subsection{Tahap Perancangan Sistem}

Setelah melewati tahapan perancangan bisnis, berikut adalah tahapan untuk merancang bisnis dan sistem dari model sistem baru yang disuslkan, sistem baru yang diusulkan menggunakan Unfield Modelling Language (UML) dimana analisa yang dilakukan sebelumnya. Rancangan sistem dibangun menggunakan tools yang ada pada UML yaitu, Class Diagram, Use Case Diagram dan Activity Diagram.

Dalam tahap ini penulis merancang sebuah sistem dengan rinci berdasarkan hasil dari analisa sistem yang sudah terbentuk, sehingga analisa yang dihasilkan akan membuat model dengan sistem yang baru untuk diusulkan. Tahapan perancangan system ini diantaranya, yaitu:

a. Activity Diagram digunakan untuk menjelaskan tentang proses bisnis berjalan pada Distro Betawi Boys terdapat aktifitas yang ada didalam website.

b. Use Case Diagram menggambarkan interaksi antar actor dengan system yang dibuat.

c. Class Diagram menggambarkan struktur kelas dari satu system dan hubungan antar kelas di dalam yang akan dirancang sebagai database pada system E-Commerce.

\section{HASIL DAN PEMBAHASAN}

\subsection{Tahapan Penelitian}

Tahap penelitian adalah langkah yang digunakan untuk melakukan penelitian ini. Tahapan-tahapan dari jalannya penelitian ini dimulai dari tahap analisa masalah yang terjadi pada penjualan Distro Betawi Boys. Setelah menganalisa masalah yang ada maka dilakukan tahapan pengumpulan data dengan melakukan observasi, wawancara, analisa dokumen, dan studi literatur. Hal ini untuk mencapai tujuan penelitian yaitu dapat meningkatkan dan mempermudah dalam melakukan pemesanan dan penjualan produk. Kemudian tahapan berikutnya adalah perancangan bisnis dengan metode BMC, lalu analisa sistem dengan metode UML menggunakan Activity Diagram, Use Case Diagram, dan Class Diagram. Perancangan sistem yang diterapkan menggunakan strategi SEO dan strategi marketing. Hasil penelitian ini adalah dengan dibuatnya website e-commerce ini membuat produk makin dikenal oleh calon pelanggan dan penjual semakin meningkat dan dengan adanya SEO untuk menempatkan suatu website agar tampilan yang muncul berada diurutan pertama mesin pencari dengan memasukan keyword. Tahapan penelitian tersebut, dapat terlihat pada gambar 2.

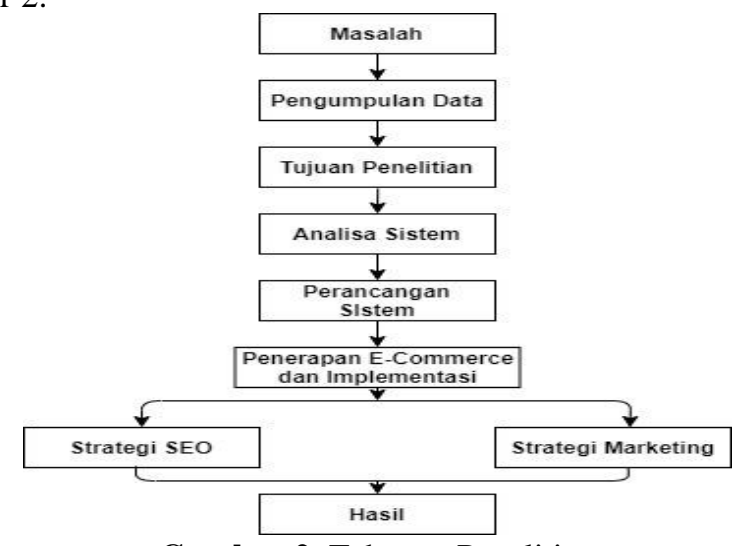

Gambar 2. Tahapan Penelitian

\subsection{Business Model Canvas}

Sembilan blok elemen yang terdapat pada strategi untuk menerapkan bisnis dalam mmbuat sebuah Business Model Canvas (BMC), bertujuan untuk merancang, mengubah model, dan menilai sistem bisnis yang ada pada Distro Betawi Boys. Business Model Canvas dapat terlihat pada gambar 3. 


\section{The Business Model Canvas}

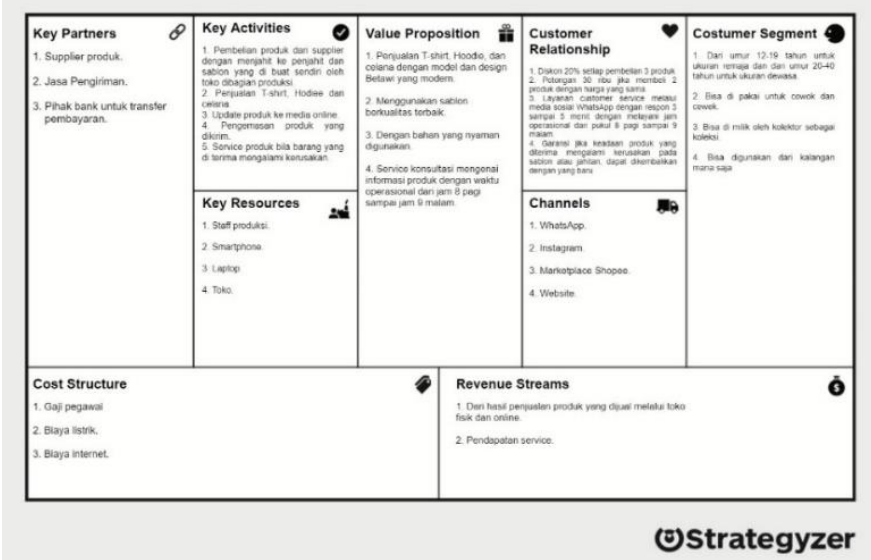

Gambar 3. Business Model Canvas Distro Betawi Boys

Pada gambar 3 menjelaskan bagan Business Model Canvas untuk Distro Betawi Boys, maka kesembilan blok yaitu:

a. Value Proposition: merupakan suatu nilai yang ditawarkan penjual kepada pembeli. Distro Betawi Boys dipercayai oleh beberapa influencer pada media social untuk mempromosikan di akun media social mereka. Dengan masuknya produk reseller dimedia social tersebut otomati produk Distro Betawi Boys adalah produk yang di percaya sebagai produk terbaik.

b. Customer Segment: Konsumen yang menjadi sasaran penjualan pada Distro Betawi Boys adalah kalangan mana saja dari kalangan remaja hingga dewasa dan bisa digunakan oleh cowok maupun cewek.

c. Customer Relationship: dilakukan produsen dalam menjangkau konsumen untuk terus berhubungan dengan mengadakan diskon dan bonus terhadap pelanggan yang sudah melampaui jauh pembelian tertentu.

d. Keys Activities: kegiatan yang dilakukan Distro Betawi Boys untuk saat ini adalah pembelian produk dari supplier dengan menjahit ke penjeahit dan sablon yang dibuat sendiri oleh pemilik toko, penjualan T-shirt, Hoodie, dan celana yang diupdate ke media online serta pengemasan produk yang dikirim melalui kurir dan service produk bila barang yang diterima mengalami kerusakan.

e. Key Partner: beberapa pihak yang ada didalamnya untuk bekerja sama dengan produsen dalam rangka agar dapat memudahkan aktifitas bisnis seperti supplier, pihak bank, dan perusahaan jasa pengiriman.

f. Channels: Distro Betawi Boys mempunyai sebuah website yang akan memperluas dan meningkatkan jangkauan penjualannya kepada para konsumen yang jaraknya jauh dari toko Distro Betawi Boys agar semakin dekat dengan calon pembeli. Serta menambahkan fitur layanan untuk bertanya mengenai ketersediaan barang ataupun keluhan.

g. Revenue Streams: pendapatan yang didapat saat ini pada Distro Betawi Boys adalah dari hasil penjualan produk yang dijual melalui toko fisik dan media online, serta media pendapatan service dari google ads.

h. Key Resources: Distro Betawi Boys membutuhkan staff produksi yang bertugas untuk membuat produk, memiliki toko sendiri dan smartphone atau laptop yang berguna untuk melakukan penjualan melalui media online.

i. Cost Structure: Distro Betawi Boys saat ini mempunyai toko fisik dan pegawai yang wajib mendapatkan gaji tiap bulannya, serta biaya operasional yang dikeluarkan untuk penunjang biaya dan lain sebagainya seperti biaya listrik dan biaya internet.

\subsection{Strategi Marketing}

Strategi pemasaran yang diterapkan pada website E-Commerce Distro Betawi Boys adalah melalui media sosial. Denga penggunaan media sossial yang Sekaran ini sebagai media pemasaran adalah karena mayoritas target pasar aktif dalam media sosial dan jangkauan pemasaran menajdi lebih luas Untuk strategi pemasaran menggunakan media sosial toko Distro Betawi Boys memilih Instagram yang diarahkan kehalan website E-Commerce Distro Betawi Boys untuk melakukan transaksi pemesanan. Media sosial hanya sebatas tempat promosi dan intraksi pelanggan dengan penjual.

\subsection{Proses Bisnis Usulan}

Pada proses bisnis usulan activity diagram diterapkan sebagai acuan dibangunnya website dibuat untuk melakukan proses bisnis usulan yang didalam terdapat proses melakukan penjualan dan pembelian produk. Berikut adalah proses activity diagram bisnis usulan Distro Betawi Boys untuk proses pemesanan dan pembayaran. 


\section{a. Proses Bisnis Usulan Pemesanan Produk}

Calon pelanggan yang akan membeli produk dari Distro Betawi Boys dengan mengunjungi website Distro Betawi Boys untuk melihat semua produk yang ada pada Distro Betawi Boys. Kemudian calon pelanggan memilih menu shop lalu memilih produk yang diinginkan. Lalu pelanggan memilih dengan mengklik tombol add to chart pada produk, jika sudah memilih pelanggan dapat mngklik tombol view cart serta menentukan jumlah yang diinginkan. Jika memiliki coupon pelanggan memasukan kode untuk mendapatkan discount. Kemudian memilih tombol checkout. Kemudian pelanggan dilaihkan masuk ke halaman form checkout, lalu pelanggan diminta untuk mengisi data pelanggan, jika belum mempunyai akun pelanggan dapat mendaftar dengan mengceklis mendaftar account, jika pelanggan sudah mempunyai account dapat langsung mengisi email yang telah terdaftar, setelah pelanggan mengisi billing details kemudaian memilih jasa pengiriman yang ada pada Distro Betawi Boys juka data yang diisikan sudah benar oleh sistem pelanggan bisa klik tombol place orde. Kemudian pelanggan akan masuk ke halaman yang berisikan nomor rekening dari toko Distro Betawi Boys dan memasukan jumlah yang harus di transfer sesuai dengan harga yang ada, kemudian pelanggan akan mendapat email berisi invoice pembelian dan jumlah pembayaran. Lalu sistem dari website Distro Betawi Boys akan memproses validasi email dimana admin dari website Distro Betawi Boys akan mendapatkan notifikasi email ada pesanan baru. Proses ini dapat dilihat pada gambar 4.

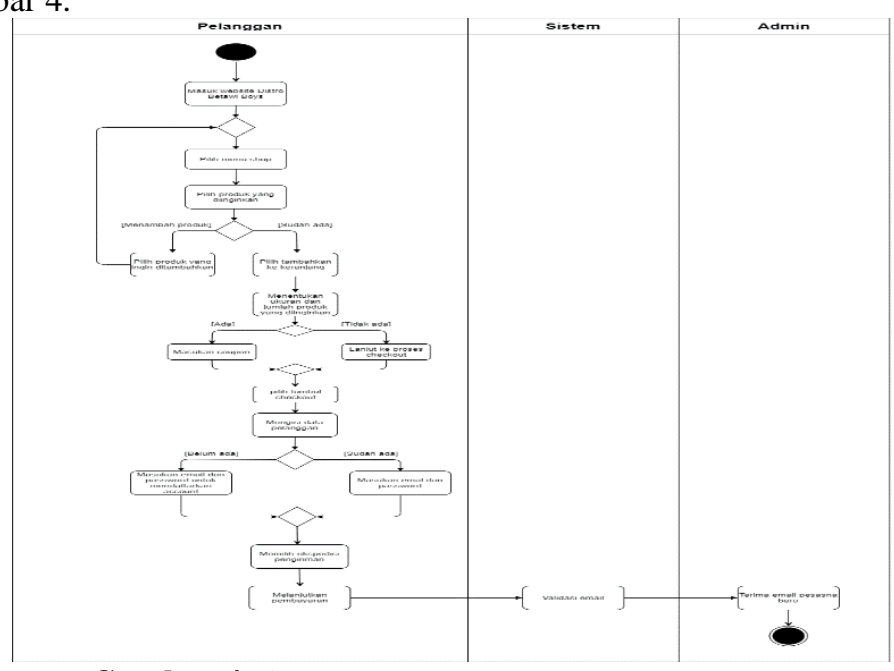

Gambar 4. Activity Diagram Proses Pemesanan

b. Proses Pembayaran dan konfirmasi pembayaran

Pesanan yang dibuat sebelumnya oleh pelanggan masuk ke proses pembayaran, dimana pelanggan yang akan ingin melakukan pembayaran melalui transfer dapat mengklik tombol select to Payment lalu sistem akan menampilkan halaman payment method. Pelanggan memilih Payment method lalu sistem akan menampilakn jumlah tagihan, pembayaran dengan cara transfer. Admin akan megkonfirmasi pembayaran dan merubah status pembayaran dan sistem akan menyimpannya. Lalu sistem akan mengirim email notif bukti pembayaran kepada pelanggan, kemudian pelanggan menerima informasi pelanggan. Proses ini dapat terlihat pada bagian gambar 5.

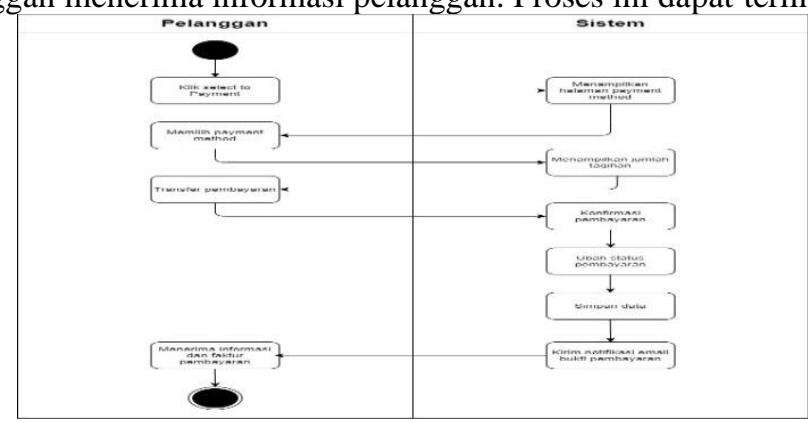

Gambar 5. Activity Diagram Proses Pembayaran dan Konfirmasi Pembayaran 


\subsection{Use Case Diagram}

Use case diagram untuk system website E-Commerce Distro Betawi Boys terdiri dari beberapa proses diantaranya use case diagram master, cetak laporan, dan transaksi. Aktor yang terlibat dalam penelitian ini adalah admin dan pelanggan pada use case diagram. Proses kegiatan ini dapat terlihat pada gambar 6.

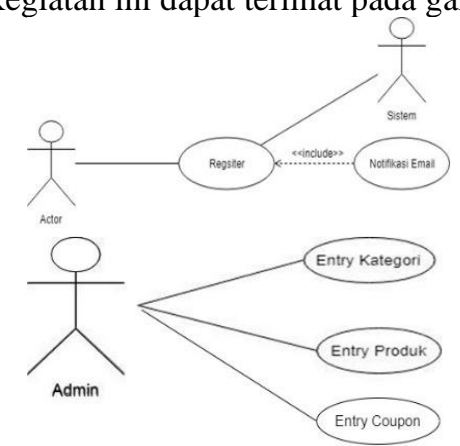

\section{Gambar 6. Use Case Diagram Master}

Pada kegiatan proses transaksi use case diagram mempunyai dua actor, yaitu actor pelanggan dan actor admin. Pelanggan adalah sebagai actor untuk melakukan pembayaran dan admin sebagai actor untuk melakukan proses pemesanan, kegiatan ini dapat terlihat pada gambar 7.

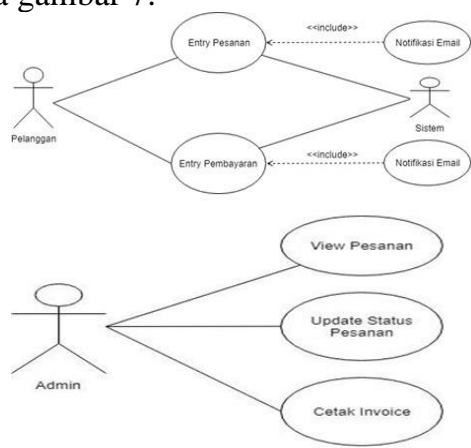

Gambar 7. Use Case Diagram Transaksi

Kegiatan proses cetak laporan use case diagram dimana admin adalah actor untuk mencetak laporan pendapatan, pemesanan, pemakaian coupon, produk, dan rekapitulasi produk terlaris menjadi kegiatan untuk proses mencetak laporan yang akan diserahkan kepada pemilik toko. Kegitan ini dilakukan pada Gambar 8.

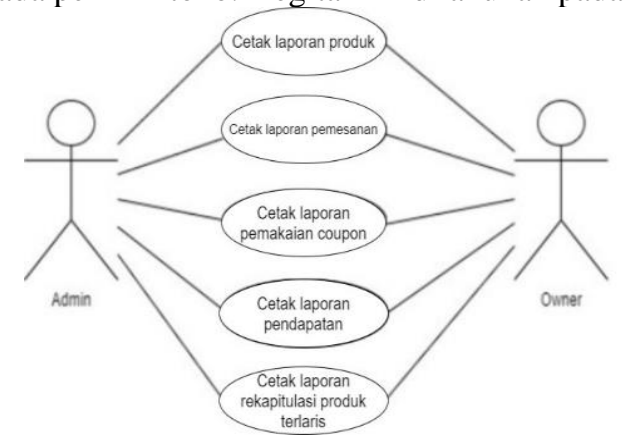

Gambar 8. Use Case Diagram Cetak Laporan 


\subsection{Class Diagram}

Proses class diagram dibuat sebagai acuan kegiatan yang dilakukan untuk terbentuknya sebuah database website, Sehingga mempermudah proses data dapat tersimpan baik pada database. Proses class diagram dapat terlihatan pada gambar 9. system website E-Commerce Distro Betawi Boys.

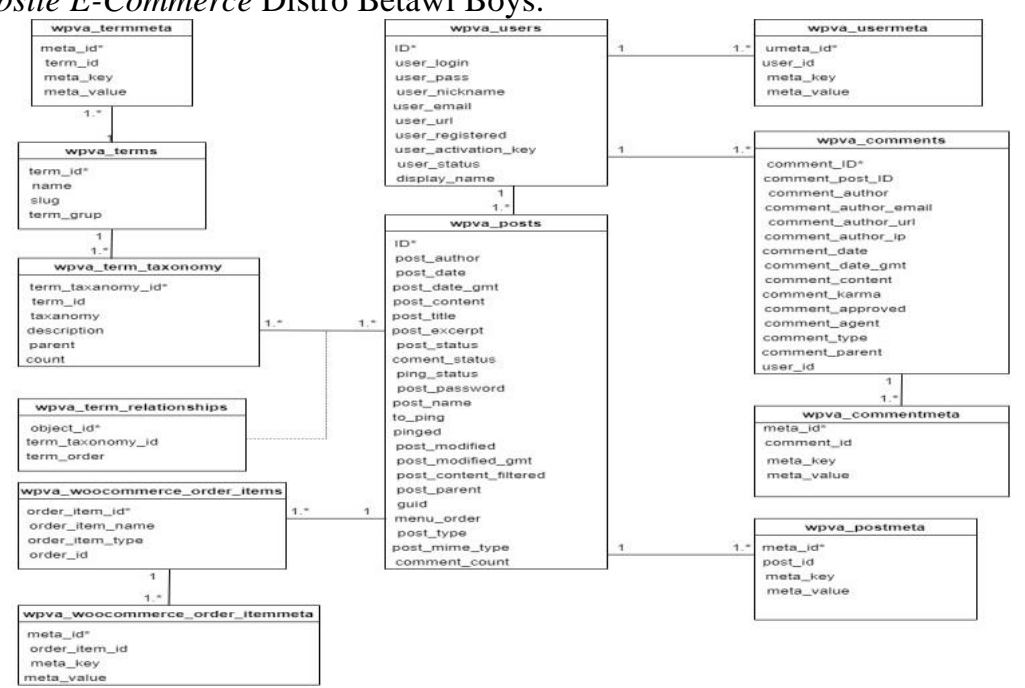

Gambar 9. Class Diagram

\subsection{Tampilan Layar}

Kegiatan untuk proses transaksi melalui media online pada wesbsite e-commerce Distro Betawi Boys dapat meumdahkan dan membantu konsumen untuk melakukan proses pembelian jarak jauh. Pembuatan sistem ini mempunyai dua tampilan, yaitu tampilan Back end dan tampilan Front end. Berikut merupakan penjelasan dan gambaran yang ditampilkan website pada Distro Betawi Boys.

a. Tampilan Layar Front end

1. Tampilan awal pada website akan menampilkan halaman awal dari website e-commerce Distro Betawi Boys dapat terlihat pada gambar 10 .

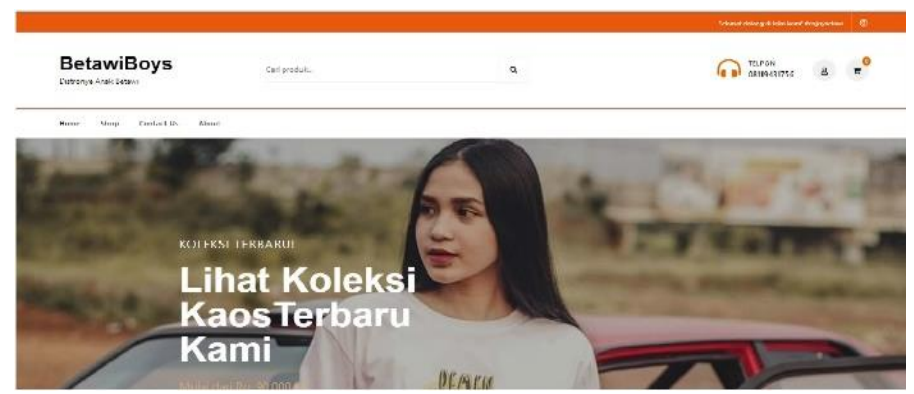

Gambar 10. Tampilan Layar Halaman Awal

2. Pada tampilan selanjutnya akan menampilkan proses add to cart dimana pelanggan yang ingin membeli produk dapat mengklik add to cart pada website Distro Betawi Boys terdapat pada gambar 11.

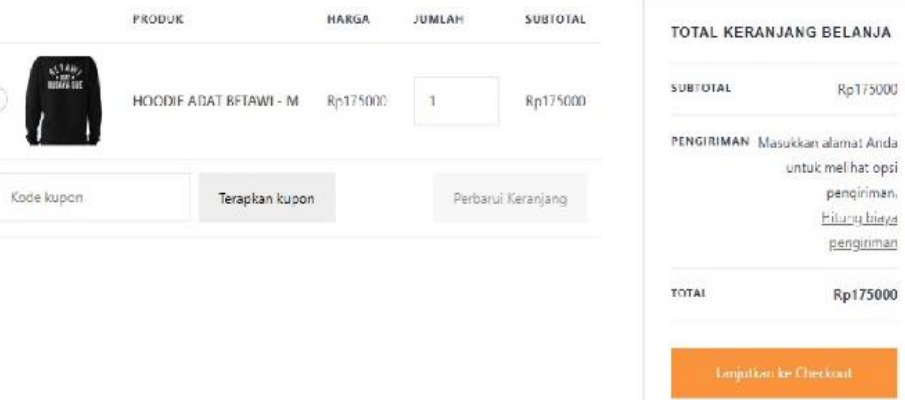

Gambar 11. Tampilan Layar Add to Cart 
3. Tampilan Produk menjelaskan Ketika pelanggan mengklik produk pada website Distro Betawi Boys terdaoat pada gambar 12 .

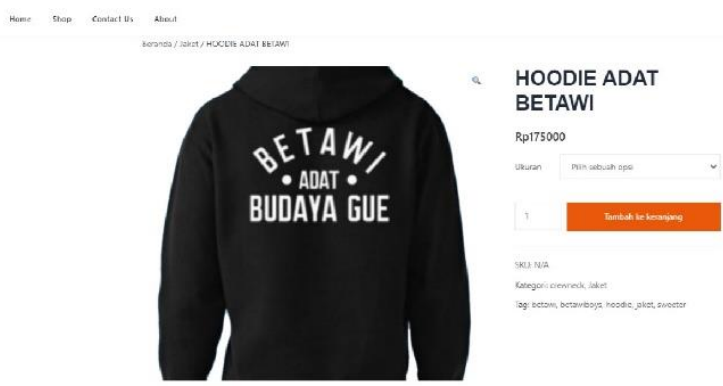

b. Tampilan Layar Back end

Gambar 12. Tampilan Layar Detail Produk

1. Bagian layar back end akan menampilkan hasil laporan pemesanan yang terjual pada tampilan website Distro Betawi Boys dapat terlihat pada gambar 13.

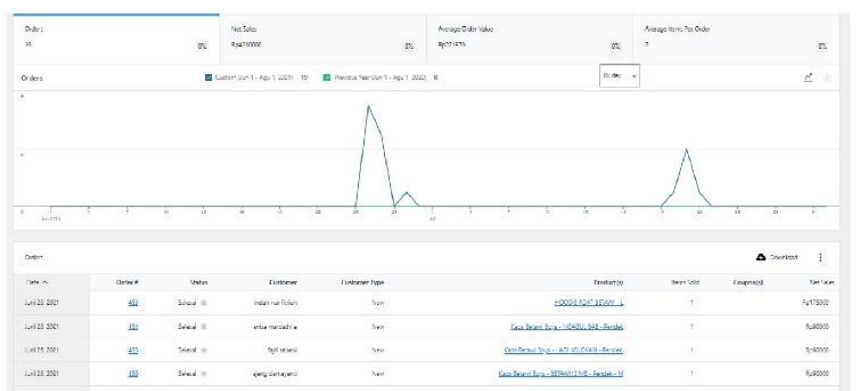

Gambar 13. Tampilan Layar Laporan Pemesanan

2. Selanjutnya tampilan back end produk terlaris akan menampilakan hasil laporan rekapitulasi produk terlaris pada website Distro Betawi Boys dapat terlihat pada gambar 14.

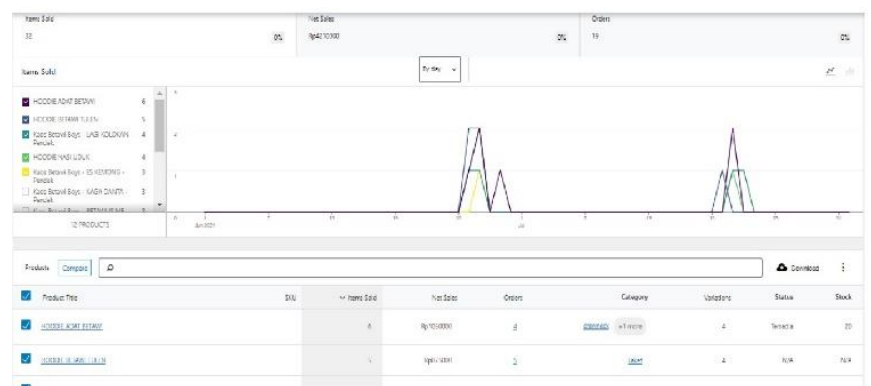

Gambar 14. Tampilan Layar Laporan Rekapitulasi Produk Terlaris

\subsection{Search Engine Optimization (SEO)}

Setelah implementasi website selesai dibuat, hal yang dilakukan selanjutnya adalah mengoptimalkan SEO. Dimana kegunaaan SEO adalah untuk mempermudah dalam mengoptimalkan SEO yaitu dengan menggunkana plugin Yoast SEO yang akan memberikan langkah yang harus dilakukan dalam mengoptimalkan SEO. Untuk mempercepat pengindekan yang dilakukan oleh mesin pencari google, maka perlu dimasukan sitemaps website betawiboys.com pada google search console. Pada Plugin Yoast SEO digunakan agar mendapatkan sitemaps.

\subsection{Hasil Pengujian Index Mesin Pencari Google}

Setelah menerapkan Search Engine Optimization atau SEO pada mesin pencari, perlu adanya proses pengindeksan pada website. Tahap ini dilakukan agar dapat mengetahui hasil dari website yang sudah terindeks oleh mesin pencari atau belum. Hal yang dilakukan untuk pengujian index pada mesin pencari dengan memasukan site://betawiboys pada kolom pencarian akan menghasilkan hasil pencarian dengan menggunakan keyword akan muncul pada halaman pertama dengan urutan 8 , dapat terlihat pada gambar 15 . 


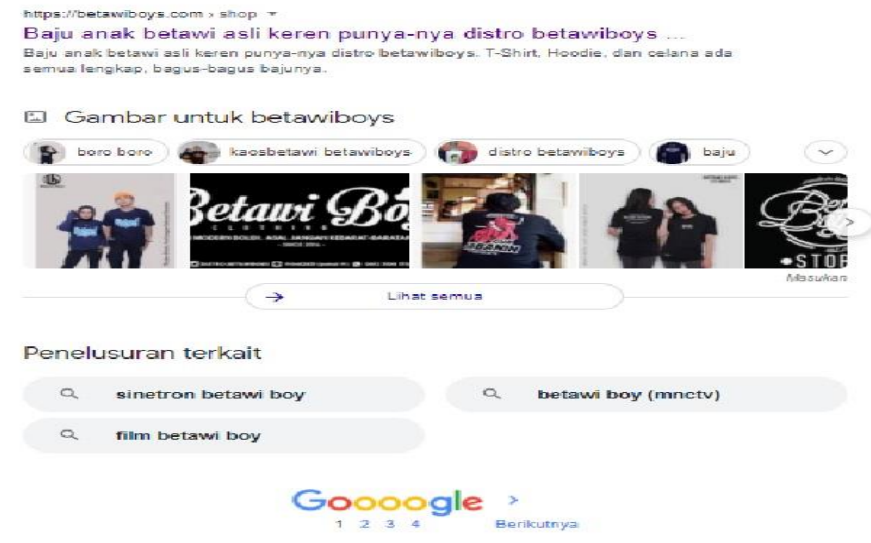

Gambar 15. Hasil Mesin Pencari Google

\section{KESIMPULAN}

Berdasarkan hasil dari penelitian dan pembahasan yang dilakukan dapat disimpulkan dengan hadirnya fitur tampilan stok produk yang update pada pelanggan dapat memberikan informasi produk sehingga pelanggan membeli produk tanpa perlu menanyakan stok produk kepada admin Distro Betawi Boys dan pelanggan dapat melakukan pembelian online jarak jauh tanpa harus datang langsung ke toko. Dengan adanya website e-commerce ini juga menyajikan bukti penjualan dan pembayaran informasi detail kepada konsumen, melalui notifikasi email dan juga dapat bersaing dan berkembang di dunia fashion. Dengan fitur SEO website e-commerce yang diterapkan pada Distro Betawi Boys akan mempermudah dalam pencarian di mesin pencari, serta meningkatkan penjualan produk yang lebih luas kepada konsumen, serta dapat memperluas jangkauan promosi dengan memalui pemasaran di internet dan google listing.

\section{Daftar Pustaka}

[1] S. Kosasi, "Pembuatan sistem informasi penjualan berbasis web untuk memperluas pangsa pasar," Pros. Snatif, pp. 225-232, 2014.

[2] G. A. P. Noor and Samsinar, "Implementasi E-Commerce Menggunakan Content Management System Untuk Pemasaran Produk Pada Lumi," J. IDEALIS, vol. 3, no. 1, pp. 552-559, 2020.

[3] D. Susandi and S. Sukisno, "Sistem Penjualan Berbasis E-Commerce Menggunakan Metode Objek Oriented pada Distro Dlapak Street Wear," JSiI (Jurnal Sist. Informasi), vol. 4, pp. 5-8, 2017, doi: 10.30656/jsii.v4i0.368.

[4] S. Wasiyanti and D. Barkah, "Sistem Informasi Penjualan Baju Berbasis Web Pada Project Distro Depok," J. Perspekt., vol. 16, no. 2, pp. 125-135, 2018.

[5] T. dwi Alperdo and G. Gata, "Implementasi E-Commerce Menggunakan Business Model Canvas Dan Ifml Pada Distro Mr Bro,” J. IDEALIS, vol. 2, no. 6, pp. 369-376, 2019.

[6] Y. M. Kristania, "Pemanfaatan Aplikasi E-Commerce Berbasis Web Menggunakan Framework Codeigniter (Studi Kasus: Distro Pak Eko)," EVOLUSI J. Sains dan Manaj., vol. 7, no. 2, 2019, doi: 10.31294/evolusi.v7i2.6197.

[7] R. Pitriyani, G. Triyono, and S. Y. Nugroho, "Pengembangan Model Sistem E-Commerce Berbasis Web Dengan Content Management System (Cms)," J. IDEALIS, vol. 4, no. 1, pp. 37-46, 2021, [Online].

[8] R. R. Rerung, E-Commerce, Menciptakan Daya Saing Melalui Teknologi Informasi. Deepublish, 2018.

[9] V. Vysotska, V. B. Fernandes, and M. Emmerich, "Web Content Support Method in Electronic Business Systems.," in COLINS, 2018, pp. 20-41.

[10] H. Stern, D. Damstra, and B. Williams, Professional WordPress: Design and Development. John Wiley \& Sons, 2010.

[11] A. Osterwalder and Y. Pigneur, Business model generation: a handbook for visionaries, game changers, and challengers. John Wiley \& Sons, 2010. 